\title{
Adolescent male orphans affected by HIV and AIDS, poverty and fatherlessness: A story of marginalisation?
}

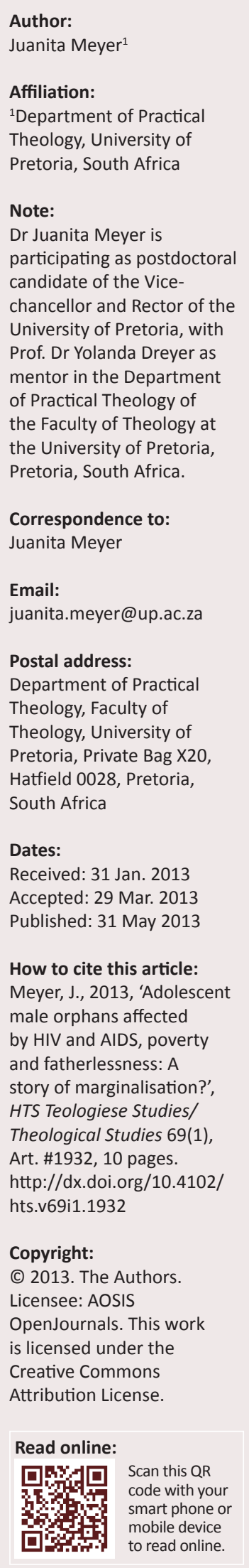

This article explores the experiences of fatherless adolescent males affected by HIV, AIDS and poverty, in order to investigate how these experiences influence the creation of their alternative, future narratives and if these experiences result in narratives that speak of marginalisation or instead, will speak of survival. Research methods from the qualitative case study research design are employed. The theoretical point of departure is a postfoundational practical theology and narrative therapy. The specific focus is on issues of marginalisation and to listen to the narratives within their contexts. The article explores and deconstructs the dominant discourses engrained within the larger socio-economic and cultural context and questions whether these narratives should be viewed as a story of marginalisation. The article concludes that it is not a story of marginalisation, but rather a story of survival, a story of hope.

\section{Research interest and question}

According to the Global Report on the HIV and AIDS Epidemic (2008), published by the Joint United Nations Programme on HIV/AIDS (UNAIDS) more than 5.7 million people in South Africa are living with HIV and AIDS. This number includes about 300000 children, and makes South Africa one of the countries affected most by the pandemic. In turn the AIDS Foundation of South Africa (AFSA) (2005) estimates that one woman for every two men is infected with HIV and that the difference is greater for women between the ages of 15 and 24 years. It is apparent from these statistics that women face a greater risk of becoming infected with HIV than men.

The fact that the mortality rate for HIV-positive women is higher than for men affects not only the statistics, but also leaves thousands of children to fend for themselves (cf. Loubser \& Müller 2011:1 of 9): 'Millions of children have been orphaned or made vulnerable by HIV/AIDS. The most affected region is sub-Saharan Africa, where an estimated 12.3 million children have been orphaned by AIDS' (Children on the Brink 2004:3). Most of these orphaned children are left behind in a 'deeply impoverished household ... [and] face inadequate nutrition and poor access to education and health care' (AFSA 2005).

It is estimated that globally of the number of orphans, about $55 \%$ are aged $12-17$, or are adolescents (Ruland et al. 2005:5 of 34). This is significant because adolescents are in a different developmental stage and at an age where they should engage in activities that prepare them for adulthood. However, because of the death of a breadwinner, many adolescents have less access to school as they 'have to assume new responsibilities for supporting the family' (Children on the Brink 2004:18). This in turn reduces their chances of getting adequate education and training, which they need in order to get a stable and secure job.

Additional consequences of the HIV and AIDS epidemic are the devastation of the family structures that a society must bear. The family structure as an institution is naturally a safe harbour in which children are nurtured and guided into ways of being, a space where gender and personal identities can be developed (see Loubser \& Müller 2011). 'People are born into families and it is in families that they make sense of themselves and the world around them (CSA work in progress)' (Barolsky 2003:14). In the context of HIV and AIDS however, important caregivers fall ill, parents die and children are orphaned, the family structure is placed under an immense burden and its ability to '... operate as an agent of socialisation, economic support, nurturance and care' is compromised (Barolsky 2003:14).

It has been indicated that most children have been left fatherless before they lost their mothers due to AIDS (Statistics South Africa 2008:74). To worsen the loss that these children experience, many fathers do not step up to their responsibilities and desert their families, possibly due to the high rate of divorce and desertion, labour migration, a lack of job opportunities and job loss, and many times, due to illness and death (cf. Mtimkulu 2006:28) 
Besides the consequences of leaving women with financial burdens and the children to look after the ill parent, the high rate of father absence is an impediment to proper childraising and has many negative psycho-social consequences on a child's development: 'The absence of the father means that children are unable to develop properly on many levels: psychologically, materially, emotionally, cognitively and physically' (Mtimkulu 2006:39).

It would seem then that at its core, the battle against HIV and AIDS entails many unjust and unequal social practices, which increase people's - but specifically women's - vulnerability to HIV and AIDS. The agents of these practices are often men, as traditional concepts of masculinity inherent in sexuality and within the traditional family structures, are still the dominant discourse (cf. Loubser \& Müller 2011:2 of 9). Rao Gupta (2000) states:

Power is fundamental to both sexuality and gender. The unequal power balance in gender relations that favours men, translates into an unequal balance in heterosexual interactions which increase both men and women's vulnerability. (pp. 1-2)

In considering all the above-mentioned results, consequences and sometimes causes of HIV and AIDS, it becomes apparent that we as a country, as a nation, have a war to face. This war is not only a war of the healthy versus the unhealthy, life versus death, or poor versus rich, but also against justice versus injustice, grace versus judgement, responsibility versus desertion, acceptance versus stigmatisation, freedom versus oppression, love versus antagonism, the individual versus the community. It's not just a war of the physical, but also of the social and cultural.

\section{Research approach and selection of co-researchers}

This research followed the design of the qualitative research approach, which means that specific theories both underpin and motivate the methodological approaches followed. Qualitative research is very much interested in the perspectives of the co-researchers; their experiences of phenomena and their understanding of their experiences of specific phenomena (cf. Struwig \& Stead 2007:12). Based on these assumptions the researcher and the co-researchers engaged in various opportunities for conversation, which increased the understanding of the researcher and assisted in the description of understanding (Loubser \& Müller 2011:2 of 9).

The case study design was used as point of departure when data was collected. Various methods of data collection were used, such as group- and individual interviews, the use of individual case studies, the development of a theme-based workbook, collateral observation, participatory observation and a literature study. Data analysis did not happen in isolation, but with the collaboration of the co-researchers. The generalisation of the findings was not the primary goal of the research process instead this research aimed to reaching an understanding through journeying with the co- researchers. Meaning making or understanding was reached as the researcher and the co-researchers deconstructed personal narratives, dominant socio-cultural discourses and developed alternative narratives (cf. Loubser \& Müller 2011:3 of 9).

Participants ${ }^{1}$ were selected according to the non-probability sampling method (cf. Whitley 2002:394) with the help of two selected non-governmental, community-based and faithbased organisations who work specifically with orphaned and vulnerable children affected by HIV and AIDS. When a list of possible participants and their details were received, the purposive sampling method (cf. Whitley 2002:395) was used to select appropriate participants according to specific criteria.

In the end, seven orphaned, adolescent male participants, who live in the vicinity of Pretoria or Johannesburg area, were chosen and invited to take part in this study as coresearchers. As part of the data collection process and coming to an in-depth understanding of the experiences of these coresearchers, they were invited to a weekend breakaway (Tree of Life Camp [TOC]) on two separate occasions (2008 and 2010), to discuss the items contained in the developed Tree of Life (TOL) and David and Goliath booklet.

\section{Theoretical points of departure}

Qualitative postmodern and postfoundational research was conducted, based on the models of the narrative approach and the seven movements of the postfoundational notion of practical theology. The empirical research conducted was based on the methods proposed by the notion of transversal reasoning which '... helps us to better position ourselves against the relativistic tendencies in some approaches within social constructionism and the narrative approach' (Müller 2005:80; cf. van Huyssteen 1997:180-192) with the aim to adequately describe and understand the embedded context.

By using the narrative model to collect and interpret data, the researcher decided to specifically use the metaphor of the Tree of Life and the narrative of David as an analogy to guide the co-researchers to reflect on their current narratives and for the development of a meaningful and purposive alternative narrative. This movement was motivated by the statement by Freedman and Combs (1996:1) that shows the powerful influence of the metaphors we choose through which we organise our lives and work on the construction of our perceptions and subsequent behaviour.

The analogy with the narrative of the biblical David provided a basis for the co-researchers to deconstruct certain discourses within their context, which in turn influenced the construction of the future narratives as future men, husbands and fathers. Therefore, this narrative was offered as an analogy to their own lives, of how their society or community assists in the construction of gender-related spiritual narratives.

1.The participants in this study gave their permission for their stories and poem to be published. Pseudonyms were used. 
The methods employed by practical theological research, according to the postfoundational notion of practical theology, should always be truthful to a specific, local and embedded context. A truthful practical theology method, according to Browning (1991:34) entails a definite, purposeful movement from context to theory and then, theory to context again. Müller (2005:78-79) in turn, referred to this process as 'the circle of practical wisdom' and accordingly he developed several minimum requirements for doing research in the discipline of postfoundational practical theology so that we are able to reflect in a meaningful manner on the experiences of the presence of God. Thus practical theology must always be locally contextual, socially constructed, directed by tradition, explorative of interdisciplinary meaning and pointing beyond the local (cf. Müller 2005:78).

These requirements have been extended into seven movements, when, if conducted, result in achieving the outcomes of the minimum requirements for a postfoundationalist practical theology (cf. Müller 2005:78). Additionally, specific methodological guidelines were developed for each movement (cf. Müller 2005:82) and were used to collect, describe and/or interpret the data of this study.

The seven movements, which correspond to the minimum requirements for a postfoundationalist practical theology are:

- a specific context is described

- in-context experiences are listened to and described

- interpretations of experiences are made, described and developed in collaboration with co-researchers

- a description of experiences as it is continually informed by traditions of interpretations

- a reflection on the religious and spiritual aspects, especially on God's presence as it is understood and experienced in a specific situation

- a description of experience, thickened through interdisciplinary investigation

- the development of alternative interpretations that point beyond the local community.

Each movement is represented by an appropriate metaphor, which elaborates on the primary metaphor of David and Goliath and which describes the nature of each movement metaphorically as it applies to the research process and the elaboration of 'thick' descriptions.

\section{The significance of describing and understanding the context}

This article elaborates specifically on the first requirement of a postfoundational practical theology, which entails the action of being locally contextual. Movement one: describing a specific context; and movement two: listening to and describing in-context experiences which correspond with the first requirement. The first movement therefore aims at describing the context wherein the adolescent male orphans find themselves, and as such describes a context infiltrated by poverty, abandonment, loss and HIV and AIDS.
This movement is supported by the imperative of the postfoundational notion of reality, to first listen to the stories of people in real-life situations, before a description of context can be attempted. Müller (2009:204) adamantly states that the aim is not to describe a general context, but a specific and concrete context. This type of description is only possible through a sincere interest in the stories of the people embedded in this specific and general context. Therefore the context of the co-researchers is first described in terms of the most significant events embedded in this context, which have an influence on the construction of their narratives.

After the description of the embedded and lived context, a description of the experiences within such a context is needed. This is movement two. The assumptions of hermeneutics help us to understand that people are characteristically dialogical, relational, interdependent, self-interpreting and agentic, within a context which has its own pre-established meanings and events of significance (cf. Thrift \& Amundson 2007:44). We can therefore deduce from this that a context is needed before experience can happen, as experience is both action and context, and from experience meaning is created. All experiences and constructed meanings are therefore embedded in context and the person's relation with that context. Thrift and Amundson (2007:44) confirm this statement by stating that, 'although human beings actively work to make sense and ascribe meaning to their lives, this always happens within the confines of history and culture.'

Freedman and Combs (1996:1) state that using the narrative metaphor can help us to 'think about people's lives as stories' and in turn, Goldenberg and Goldenberg (2008:44) state that people tend to organise their experiences in the form of a selfnarrative. The narrative approach through the suggestion of listening to the stories of people, makes it possible to use these narratives to gain useful information about how people experience their life and significant events they come to face during their life time.

The second movement of the postfoundational notion of practical theology assisted the researcher in listening to the narratives of the co-researchers, who indicated their experiences within their context in relation to significant events. The researcher also employed the method of deconstructive listening in enabling her to be sensitive to any indication of dominant discourses inherent in the descriptions of the context.

The analogy of 'battlefield' is used to represent movement two of the postfoundational notion of practical theology, and refers to the description of the stage on which the battle will take place. This analogy is chosen because it became apparent that the co-researchers of this study were indeed fighting a battle. As with any war, it is to one's advantage to know the battlefield - to know where your enemies come from, what shelter is provided and what armour is available from the battlefield, hence the activity of sending a scout to explore the battlefield and the enemy. This scouting of the battlefield might be seen as an analogy of the process of deconstructing dominant discourses (cf. Loubser \& Müller 2011:7 of 9). 
Similarly the co-researchers are referred to as the (post) modern-day David, referring to the narrative of the biblical David used during this study as an analogy of their own lives, of how their society, or community assists in the construction of gender-related spiritual narratives. The narrative of the biblical David provided a basis for the co-researchers to deconstruct certain discourses within their context, which in turn influenced the construction of the future narratives as future men, husbands and fathers (Loubser \& Müller 2011:9 of 9). This method to use metaphors and analogies in deconstructing dominant discourses, and subsequently in the creation of an alternative narrative, forms part of the methodology of the narrative research model.

\section{The battlefield of the (post)modern day David}

'I firstly lost my mother, secondly it was my brother and lastly it was my first brother during my matric year in 2008 ... It didn't hurt by that time because I was little but now for the fact that I starting to experience life it is starting to hurt ... I miss everything about them, I miss things like their love, tender and care. I also miss their support emotionally and financially'. (Molimi, TOL camp, group discussions and interviews with co-researchers, Sikelele Camp site, Magaliesburg, 26-28 February 2010)

'... my mother passed away last year on the 3rd of August, well as I've said she was a kind person. She wanted something big in life but Satan was so jealous and nothing worked out until she get sick for 3 months and then passed away ... the only challenge that I went through and still going through was the one of my father. When I tried to give him a second chance in calling me his son after leaving me for no reason.' (Manqoba, TOL camp, group discussions and interviews with co-researchers, Sikelele Camp site, Magaliesburg, 26-28 February 2010)

'I firstly lost my little sister followed by my dad then my mom. I can't remember about the first two people but mother was the best, humbled at all times ... my mother she used to live far from me and come see me at the end of every month because of her job, she had cancer then she passed on.' (Kgotoso, TOL Camp, group discussions and interviews with co-researchers, Sikelele Camp site, Magaliesburg, 26-28 February 2010)

The above mini stories illustrate a context which is deeply embedded in a world that has left many young boys abandoned and alone. This context is partially part of the global context, which is infiltrated by a reality of HIV and AIDS, poverty and abandonment. This global epidemic however, deeply engrained in the context, has infiltrated the personal and subjective lives of boys and girls at a crucial stage of their lives, when they form an identity of who they are; where they come from; and where they are going. This specific context imposes additional responsibilities on these vulnerable young minds, to such an extent that they are blinded to visualise a future. Instead, these boys are exposed to a life where they have to take responsibility and accountability for their own lives, and the decisions they make - decisions normally pertaining to the mature adult - long before society has equipped them to survive in the world.
In the 'scouting' of the context, six dominant phenomena were identified in the make-up of the context, which are noteworthy of the description of our 'battlefield' and which might influence the writing of future narratives.

\section{A context of loss and orphanhood}

All the boys are from a Black African background and most of them were born in rural areas outside the city of Pretoria. Most of their mothers moved to the city in search of job opportunities, and some only came to live with their mothers later in their lives. Six of the boys chosen as co-researchers lost their mothers to death at least four years prior to this study; five of the boys were abandoned by their fathers and two boys (twins) lost their father during a gunfighting incident when they were little, and subsequently did not know their father. All the boys, except one, are double orphans.

The above stories clearly show how the loss of a mother creates a vacuum in a child's life, especially because she is often the only stable nurturer in the family. The participants in this study stated that they do not only suffer physical loss, but also emotional and psychological losses as they have no one who supports them, love them and guide them into adulthood. It is clear that the loss caused by the HIV and AIDS environment, is not only one-dimensional, meaning that it causes orphanhood only; it also causes a loss of income and with the loss of income one loses one's sense of security. By having no loving and caring adult in the house, children also lose a sense of stability. The result of having no adult role model in the house - especially as a child who develops into adolescence - means that a child loses an opportunity to develop a stable identity. This unstable identity causes children to 'float' around senselessly, not prioritising education and not developing meaningful stable relationships.

The list of the consequences of living in the HIV and AIDS environment are endless. Foster (2006:1) states that the economic and social effects of HIV / AIDS on children include malnutrition, poverty, neglect, migration, and homelessness.' He further states that these children might also suffer from psychological effects such as depression, guilt and fear, which in turn might result in long-term mental health problems. The consequences of these are that children's access to an adequate standard of living, health and education are compromised, and that they might become vulnerable to various forms of exploitation, poverty, HIV infection and unemployment in adulthood (cf. Foster 2006:1). It is clear that children suffer multiple losses in the face of the HIV and AIDS epidemic.

\section{A context of paternal abandonment}

Of the seven co-researchers who took part in this study, six of the boys lost their mothers due to death; five of the boys were abandoned by their fathers and two boys (twins) lost their father during a gun-fighting incident when they were very little, therefore they did not know their father. 
Some of the co-researchers described the absence of their fathers as a void in their lives and how it felt when the other children spoke about their fathers and what they did together. One emphasised the lack of a role model and feelings of rejection, whilst another expressed his lack of nurture and care. Another co-researcher also expressed ambivalent feelings, stating that although his father used to physically abuse him and his mother, he still feels his absence in his life, especially when other children speak about their fathers. One of the co-researchers was raised by his stepfather and states that his stepfather is more like a biological father to him, thereby illustrating that a father does not necessarily need to be a biological parent. In all these narratives, the children unanimously expressed the void in their lives, in not having a father.

Mtimkulu (2006:38) found that about 50\% of Africa's children are raised without a father. Possible causes for this abandonment are multiple, but nevertheless result in some form of trauma experienced by the children, such as the effect of poverty and exposure to violence, as 'several children had lost their father, not to AIDS but to gun fighting' (Denis \& Ntsimane 2006:242).

It was found in numerous studies that children who grow up without a father figure experience many hindrances to their development in various dimensions. Mtimkulu (2006:39) for example, found that the absence of a father in a household might influence the development of children on many levels: 'psychologically, materially, emotionally, cognitively and physically.'

In the research undertaken, Furstenberg and Harris (1993), found that adolescents who can strongly identify with their father are $80 \%$ less likely to go to jail and $75 \%$ less likely to become unwed parents (cf. Allen \& Daly 2007:12). Studies conducted by Moore and Chase-Lansdale (2001) found that the risk of becoming sexually active at an early age is greatly reduced by living in any type of married household; whilst studies by Flouri (2005) found that when a child experiences father involvement he or she is less likely to become socioeconomically disadvantaged and experience homelessness. Furthermore, children who are raised without fathers seem to be more likely to exhibit conduct problems at school, such as an inability to pay attention, being disobedient, being expelled frequently or suspended and also poor school attendance. They are also more likely to drop out of school thereby forfeiting their opportunities for education and attaining a good job. Subsequently these children were found to have to repeat a grade, are less likely to complete high school, less likely to seek opportunities for further education and more likely to be unemployed as adults, thereby increasing the likelihood of having poor labour relations (cf. Allen \& Daly 2007:12).

It seems that a child's moral development is also influenced by the absence of a father figure. Hoffman (1971) found that the absence of a father in the lives of boys may cause a lower score on several moral indexes which measure 'internal moral judgement, guilt following transgressions, the acceptance of blame, moral values and rule conformity' (cf. Allen \& Daly 2007:13). Studies undertaken by Hetherington and StanleyHagan (1997) seem to show that both boys and girls who have been raised without a father, have a lower ability to delay gratification, thereby having poor impulse control over anger and sexual gratification, and tend to have a weaker sense of what constitutes right and wrong behaviour (cf. Allen \& Daly 2007:13).

Additional studies seem to have found a relation between the absence of a father and the development of emotional and psychosocial adjustment problems. Allen and Daly (2007:13) state that adolescents who were raised without a father exhibit a variety of internalising and externalising behaviour. For example, boys who were raised in father-absent homes were found to be more likely to have feelings of unhappiness, sadness, depression and show signs of hyperactivity; whilst both boys and girls tended to develop anxiety disorders and exhibit conduct problems (cf. Allen \& Daly 2007:13).

Adolescents are also more severely influenced by the absence of a father figure than younger children. It seems that adolescents, who lack a father figure in their upbringing, are more likely to be sexually active at an early age and engage in sexual activities on a more frequent basis. Subsequently the girls are more likely to become pregnant as teenagers or have illegitimate children as adults (cf. Allen \& Daly 2007:15). Young men are also more likely to not live with their children if they were themselves living in a home without a father (cf. Allen \& Daly 2007:15).

Fathers function as an essential source of practical, financial and emotional support for mothers, which in turn enhances the relationship that a child has with his or her mother, thereby facilitating a healthy development of the child. It is important to note that a father's social capital - in the context in which the mother or other significant others do not have the financial means - can greatly enhance a child's access to various opportunities, privileges and social networks, which provide a child with a multitude of opportunities to develop into a healthy and responsible adult (cf. Allen \& Daly 2007:30). It seems then that the financial income a father can provide is not a trivial matter with regard to the child's development, even though it might be a great gender stereotype. When the economic status of a family is increased, stress is removed from the mother thereby enabling her to be a more patient and caring mother. A father's financial contribution inevitably helps the child to better educational opportunities, which increase the quality of a child's relationship with teachers and other authoritative people, and also the type of friends that he or she will make. However, the father's absence does not necessarily mean a lack of financial means for his children and his involvement does not necessarily refer to financial involvement. As stated before, his absence has many psychological, emotional and psychosocial consequences for the child. 
On the other hand, father involvement does not always guarantee healthy development. Many fathers are highly involved with the lives of their children, but not necessarily in a good way. Studies by Jaffe et al. (2003) found that when a father is engaged in antisocial behaviour, the children also exhibit more conduct problems, both at school and home (cf. Allen \& Daly 2007:30). Morrell (2006:17-20) also provides several examples of where a father is physically present in the lives of his children, but often emotionally absent and abusive. He reports that this results in much harm, even more so than the absence of such a father.

In understanding the above findings, it becomes important to acknowledge that parental activities and engagements occur within a complex context which also entails various other influences. A child's development is not only shaped by the father's involvement, but also qualitatively shaped by interactions with various other people, for example teachers, neighbours, peers, siblings and other significant people, such as the extended family. These, combined with other cultural and economic conditions, interact with each other in shaping a child's development in various domains. Allen and Daly (2007:30) argue that the impact of an absent father moves in accordance with several directives, such as having no co-parent; experiencing economic loss or disadvantage; experiencing social isolation and disapproval; experiencing perceived or actual abandonment that relates to psychological distress, and perceived and experienced conflict between parents (cf. Allen \& Daly 2007:30). They further argue that these mechanisms might be more powerful in creating deleterious effects on children, combined with the absence of the father figure, than just the absence of a father. It is therefore necessary to consider the multidimensionality of father involvement in relation to various variables within the context, such as other relationships and social class issues. Thus the effects of father absence should be explored by considering the effects of its opposite, which are the effects of father presence (cf. Allen \& Daly 2007:30-31).

This study acknowledges that it becomes very difficult to determine exactly what the effects of the absence of father involvement in the development of a child are, as we cannot exclude other possible influences, factors and determinants (cf. Allen \& Daly 2007:27). Nevertheless, it would seem that the presence or the absence of a father can, directly or indirectly, enhance or inhibit the development of a child.

\section{A context of gender and sexuality}

The HIV and AIDS epidemic is fuelled by much more than just promiscuous sexual practices. The fragmentation of gender identities and the inequalities between the two genders are only some of the social practices affecting the spread of HIV. This is affirmed by Barolsky's findings (2003) who states that:

gender and sexuality have become recognised as critical to an understanding of both the rapid spread of HIV/AIDS within the South African context, and the way in which the disease has developed. (p. 36)
Inherent in these practices are the concepts of gender and sexuality of children who are raised without both parents and for children who witness physical and sexual abuse or have experienced it themselves. It would seem then that our children do not have a healthy paradigm of 'being a boy' or 'being a girl'. When moving into puberty, both boys and girls experience a sudden development of hormones and change in their bodies. They have to make sense of this by using skills available to them in society - a society preoccupied with promiscuous sex and the use of sex to gain power.

This epidemic makes us aware of the powerful cultural and societal discourses which tell our boys and girls how to be in this world; it is a discourse which is not sensitive to equality, healthy practices and age; a discourse which puts our young in positions where they are at risk. Therefore, amidst this epidemic we have to take a closer look at cultural and societal discourses underlying the notion of gender and sex, as this is where change must take place. Barolsky (2003) rightly states:

... the epidemic must also force a reappraisal of the notion of 'adolescence' and the restrictions placed by society on young people. HIV / AIDS is redefining and challenging as never before our understanding of what constitutes 'adult' and 'adultness' in terms of rights and behaviours and 'adolescence' in terms of rights and behaviours. (p. 19)

Most literature has focussed on how females are the victims of sexual oppression, dominance and abuse, experienced at the hands of their counterparts. Everyone is in agreement that the construction of male sexuality is at fault for these practices, but for unknown reasons these constructions are not effectively addressed to influence change - women are the focus of all interventions, but still they lack the power to successfully negotiate safer sex. Barolsky (2003:38) makes us aware how the constructions of sexuality amidst an era of HIV and AIDS, still prefer the affirmation of male power through sexual acts and notions of male sexuality, but place the blame for the origin of the disease with women. Subsequently the notion of male authority is not questioned and women still struggle to set new types of sexual boundaries.

If any change in these practices can take place, the negotiations must originate with men. Change must start with men and society's messages about what it means to be a man. Barolsky (2003:37) states that constructions of male sexuality within our societies on the one hand pose men as victims of women's primal charms; but on the other hand urge men to be the initiator of sex and to have sex with multiple partners, in order to be seen as a man. She states that being the initiator of sex and having multiple sexual partners is seen as an essential marker of manhood' (Barolsky 2003:37).

Underlying this concept of manhood is a meaning-making process constructed by issues such as sexual power and control. Similarly, in the context of manhood and its meaning, Cornell, Reid and Walker (2003: 26) endeavoured to find out how men prove their manhood. Their findings included the identification of a certain dominant behaviour in South African men that asserts their manhood, and includes the 
exercising of control over women and engaging in coercive sex. They add that 'of course, not all men behave in this way' (Cornell et al. 2003:26). It would seem then, that there exists a skewed paradigm of manhood and sex, and of gender and sexuality in South Africa, and that this paradigm - these social constructions - might be a major contributing factor to the spread of HIV and AIDS.

\section{A context of poverty}

All the boys live in conditions of extreme poverty and are registered, either with the organisations Heartbeat or Pen as 'orphaned and vulnerable' and receive material support, such as monthly food parcels. They also have access to the organisation's psycho-social support services, such as weekly support groups or therapy and counselling and academic support services such as assistance with homework and studying. All the boys were exempted from paying school fees whilst they were at school (some of the boys were at school at the start of this study, but completed matric in 2009) and are dependent on the two organisations for receiving material and other donations.

The HIV and AIDS epidemic does not exist, and is not maintained in isolation. It is both fuelled and partly caused by extreme levels of poverty that a majority of South Africa's citizens experience. Denis (2006:15) affirms this by stating that 'poverty is a result of and a cause of HIV and AIDS.' It seems that HIV in itself is opportunistic in that it flourishes amongst communities that are already labelled as the marginalised as they suffer of a low-economic status. Barolsky (2003) brings to our attention that disease does not operate as:

an independent variable but as a highly visible marker of social power. It traces the outlines of hierarchies already deeply entrenched but usually embedded but unremarked in the ordinary fabric. (p. 18)

The low socio-economic status means a lack of income, leaving many people hungry; being hungry means that one lacks certain essential nutrients, nutrients which are essential for the healthy functioning of the immune system. Therefore already on a biological level these people are more vulnerable to infection. Once infected, a poor person does not necessarily have the means for medical assistance, such as getting tested, or getting treated. Besides the fact that they cannot afford vitamin supplements, they often cannot afford transport to the clinics or hospitals. Low economic societies are also marked by a high level of crime, an attractive alternative to the many men who cannot find a job and have nowhere else to go to make a life for themselves. Poor communities also experience, more than any other social class, the effects of drug abuse, sex work and family abuse. In the townships, manhood is often equated with wealth, as one of the coresearchers stated: 'money makes a man' (TOL Camp, group discussions and interviews with co-researchers, Sikelele Camp site, Magaliesburg, 26-28 February 2010). When men cannot prove their manhood through the job they do or the money they make, they resort to other social delinquent practices such as domestic abuse and rape, which further fuels the spread of HIV.
The poorest of the poor are also preyed on by malicious rich men, who abuse young women who are already in a vulnerable position, for their own sexual satisfaction. One girl, 15 years of age, stated: 'I used my body just to survive [...] I would sleep with someone even if I didn't love that someone so long as he would give me money' (Demmer 2007:45). Elfenbein (2005:11) also found that many women engage in transactional sex because of their low socioeconomic status. This is a means to an income which is used to survive and support themselves and their families.

It would seem then that many young women and men would rather take the risk of contracting HIV and AIDS, just because their need to survive on a daily basis outweighs their need to be healthy. When looking at these findings and the detrimental context in which HIV prospers, one might go as far as to state that our main enemy might not by HIV, but rather poverty.

\section{A context of poor psycho-social development}

It is noteworthy to state that three boys completed their matric studies in 2009 but only one boy passed, whilst the other two boys failed two subjects and wrote re-examinations in 2010. The one boy who passed received a bursary to study Information Sciences at a college in Pretoria and is doing quite well.

It has been mentioned that more than half of the children orphaned in South Africa are between the ages of 12 to 17 (cf. Children on the Brink 2004:17). It seems as if adolescents make up the majority of orphans. The question is what are the effects of orphanhood on children between these ages, or children who find themselves at this crucial developmental stage?

Children on the Brink (2004:17) states that key development experiences occur during adolescence, such as physical and sexual maturation, a progression towards social and economic independence and also the development of an identity. Attending to these events becomes crucial in the context of the infection of HIV, as these children are vulnerable in becoming the victims of sexual exploitation or because they engage in various sexual activities, become vulnerable in getting infected with HIV and other sexual transmitted diseases.

Additionally it has been found that adolescents who have been orphaned understand the loss they have experienced, but find it difficult to express their feelings, worries and anxieties regarding this loss. Many times they may seem to be coping with the loss, but nevertheless experience depression and hopelessness, and might even feel resentment and anger at the death of a parental figure in their lives. These feelings can subsequently lead to 'a sense of alienation, desperation, risk-taking behaviour, and withdrawal' (Children on the Brink 2004:17).

On the socio-economic level, adolescents specifically suffer at the hands of poverty. The need to financially support 
themselves and/or their siblings and the need to attend school to obtain an education are continuously in tension. At the end of the day they might either engage in risk behaviour to attain money, or they might not attend school as they need to take on a job (cf. Children on the Brink 2004:18). Some of the adolescents, who manage to balance both school and the worries regarding finances, inevitably struggle to get good grades or even pass the year. Besides the obvious struggle for survival, the 'economic hardship can also deprive adolescents of much needed recreation and participation in community activities' (cf. Children on the Brink 2004:18). These activities are also aimed at integrating an individual into society and teaching them important life and social skills. The outcome of not being able to enjoy one's childhood has psychological consequences such as depression, hopelessness and risk behaviour which might in turn lead to the practice of unsafe sex and the abuse of illegal substances (cf. Children on the Brink 2004:18).

It is clear that adolescence in the context of HIV and AIDS is a stage marked by increased sensitivity to risk behaviour and, because of an increase of responsibilities thrust upon the adolescents by the loss of an adult and the context of poverty, they do not have the opportunity to develop into healthy adults. It is also clear that if we want to make a change, if we want to halt this disease in its tracks, we need to invest all of our interventions, time, energy and resources into this generation, providing them with some form of relief, support and guidance.

\section{HIV and AIDS, poverty and gender relations within informal settlements in South Africa}

It cannot be stated with full confidence that the mothers of all the co-researchers died of an HIV-related illness, as the death certificates indicate the opportunistic disease as cause of death, as opposed to directly ascribing the cause of death to AIDS. Some of the boys suspect that their mothers died of an HIV-related illnes, two boys state cancer as cause, whilst the remaining boys do not know the cause of their mothers' deaths - they only know that the onset of the illness and that death was unexpectedly sudden.

All the co-researchers in this study are either living in or have lived in an informal settlement. Informal settlements are generally identified by a lack of resources and extreme poverty. In turn, as we have seen formerly, poverty is a deterrent in the spread and maintenance of HIV and AIDS. A Treatment Action Campaign (TAC) briefing paper (Geffen 2008) states with some confidence that most people who are infected with HIV or have AIDS in South Africa, live in informal settlements. Their research data suggest that housing and related living conditions play a role in the transmission of HIV, and that informal settlements generally house people from a low socio-economic background, as many of the residents do not own a house, but live in a shack (Geffen 2008). The Treatment Action Campaign has also found that the residents of the informal settlements in South Africa are currently most at risk in becoming infected with HIV (cf. Geffen 2008).
An understanding of the socio-economic context and the discourses at work in informal settlements is important to understand the experiential context of the co-researchers of this study. One can ask anyone living in an informal settlement or who has been in an informal settlement before and they will tell you that different rules than in a suburb, apply there. It is interesting to note when one enters an informal settlement, in the middle of the day in the middle of the week, groups of men will sit in a circle, around a fire and drink beer. This is indicative of the high unemployment rates of people living in informal settlements, which gives way to the powers of poverty and subsequent crime to infiltrate the lives of the residents.

In informal settlements the prevalence of rape as a sexual crime is especially high. Harvey and Kehler (2005:3-4) declare that 'in South Africa, statistics on rape vary between 52000 reported cases a year [...] to 1.69 million.' Vetten and Bhana (2003) mention that one in every two women have a chance of being raped in their lifetime, whilst a woman is being raped every 26 seconds in South Africa. Furthermore it is believed that one in four women is in an abusive relationship and one woman is killed by her intimate partner every six days.

The reality is also that the majority of the victims of these assaults are women, and the majority of the perpetrators are men. Barolsky (2003:38) states that manhood is defined by the concept of sexuality and sexual promiscuity, and if men cannot prove their power as a man through the amount of money they have, they will seek alternative ways to prove their manhood: 'Constructions of sexuality in the era of HIV/ AIDS attempt to affirm male power through the performance of sexuality.' This is affirmed by a study conducted by Cornel et al. (2003:22) in which they argue that 'sex is also about power - who initiates sex, who makes the decisions [...] these decisions are contested because relationships between men and women are unequal.'

Within the township culture it seems as if unequal gender relations are quite prevalent and that many families are without a male in the house. This is significant as many young girls fall pregnant and they are left alone to care for the children - the father denying any responsibility, targeting the next vulnerable women in a conquest to prove his manhood. Demmer (2007:44) found during one of his interviews that it were most often women who had the primary responsibility of supporting the family. In most cases, it was the grandmother who had to care for the family after her children had died and there was no one to look after the grandchildren. Sometimes entire households depend on the social grant that the elderly receive in South Africa. It is also quite common for households to be headed by the oldest living child. The General Household Survey (Statistics South Africa 2008:76) states: 'there are a 150000 children living in a total of 79000 child-only households across South Africa.'

It seems then as if the social, psychological and economical context inherent in an informal settlement is not the ideal 
environment for any child to develop into his or her full potential; nevertheless informal settlements are a reality for many of our children and adolescents.

\section{A battle of marginalisation}

The concept of marginalisation is defined as:

... the overt actions or tendencies of human societies whereby those perceived as being without desirability or function are removed or excluded (i.e., are 'marginalised'...) from the prevalent systems of protection and integration, so limiting their opportunities and means for survival. (Anupkumar 2013:3 of 16)

One might be inclined to conclude that the above narrative is one of marginalisation, and rightly so. However, the narrative model speaks against such statements (referred to as thin descriptions), which lead to the creation of thin conclusions. To impose such a label onto the narratives of the co-researchers is to limit their potential for creating alternative narratives, which free them from the imprisonment of just such thin conclusions.

Thin descriptions, are ideas about oneself created by other people, or by oneself in relation to other people and this leaves little space for movement. Alice Morgan (2000:12) states that thin descriptions are very narrow and simple, which leaves little space for complexities and contradictions. Thin descriptions inhibit people in exploring and articulating their own meanings of their actions within a specific personal context. As such, thin descriptions lead to thin conclusions, which in turn are expressed as truths about a person's identity or character. These thin conclusions are very destructive and disempower people as their identity and character or even their future narratives are then built on concepts which are negative and absolute. With these conclusions people are doomed to failure and stagnancy (cf. Morgan 2000:12-13). Morgan (2000:13) affirms this by stating that the thin conclusions, drawn from problem-saturated stories, disempower people as they are regularly based on terms of weaknesses, disabilities, dysfunctions or inadequacies.

In affirming the negative power of thin descriptions and conclusions, Goldenberg and Goldenberg (2008:368) state that 'positive characteristics are obscured or hidden by the thin description-inspired story.' Thin conclusions also have the power of affirming themselves, by encouraging the person to gather more evidence which supports the dominant problemsaturated narrative and its related thin descriptions of the person. This increases the power that these descriptions have over the narrative of the person to such an extent that when positive characteristics are actually revealed by the person, it passes him or her by without notice: 'Thin conclusions often lead to more thin conclusions as people's skills, knowledge, abilities and competencies become hidden by the problem story' (Morgan 2000:13-14).

On the other hand, it is also important for the researcher and co-researchers to deconstruct the dominant socio-cultural and historical discourses with the aim of discovering just such thin descriptions and thin conclusions people have about themselves, so that these can be transformed into 'thick' descriptions and conclusions. It is also important to expose all unjust social phenomena, in our quest to liberate and free the victims of such social inequalities and in giving the marginalised a voice. However, our first responsibility on a personal level, is towards our co-researchers, to free them from the chains of such social inequalities; to change their mindset of being a victim to that of a survivor - so that they can write a story of hope, of freedom of choice and responsibility, a story of future possibilities, amidst such a seemingly dire context. This must however be done by not minimising the impact of unjust practices of society on the narratives of the co-researchers, but rather by increasing the skills of the co-researchers to rise above these unjust and marginalising practices by creating a story of hope and strength which opens up new possibilities and ways for living.

By understanding the context in which the story of HIV emerges, one can better understand the various factors that contribute to the narratives of the co-researchers of this study. It is imperative to remember that the creation of an alternative narrative will also be embedded in this context, as this is after all their home. However, it is possible that an alternative narrative can motivate a 'moving out' of this context. The idea is to make the co-researcher aware of these discourses, embedded in context, culture and all other social practices, so that they can better and more realistically rewrite a future narrative which is in fact attainable and satisfactory, keeping in mind that this future narrative will also to some extent be maintained by its specific playing field or context. The narrative model postulates that this context can be interpreted in various ways, and identified unique outcomes can open up new avenues for exploring ways in which this context can become a story of hope.

Therefore the battle of marginalisation is in actual fact against the idea or the tendency of labelling our story as one of marginalisation. The co-researchers' stories must not become stories of marginalisation, but they should rather become stories of 'winning the battle against marginalization.' This battle can really only be won when new stories emerge from this context, stories which free them from thin descriptors and thin conclusions.

In conclusion, one such alternative narrative (in the form of a song), written by two co-researchers (the twin brothers), illustrates how a story of hope, a story of survival can emerge from such a problem-saturated, and seemingly marginalised context:

\section{KEEP ON PUSHING}

This one goes out to anybody who has lost people they love the most - the most important people in their lives. I just want to give you an inspiration, you know what I mean?

And it goes something like this:

I went through the struggles man, I cried in this life

Life is hard when you ain't got parents, but you got to step it up And focus on your dreams and the goals to achieve

Even though it's hard and I'm moving on my own, I pray for a guide 
Questions running in my mind - Is God really there? Does he really hear? Wanna look alright

And my granny ain't here, she got shot - nine bullets in her body, Mommy rest in peace, oh I miss her every day

I got backstabbed by a friend, I don't bleed,

My twin on the side, you're the person I can trust,

I can let my soul shine

And stay strong

Have faith in myself,

Believe that I can do it

And a future so bright

from the dark to the light

Tomorrow be a blessing if today was a gift

Life has different stages

Nothing stays the same,

But I still broke through (still broke through)

After all that I've been through, (I've been through)

I still keep pushing higher (pushing higher)

Even though it seems so far (seems so far)

I'm reaching up to my dreams (my dreams)

And you can't tell me a thing

I can't go to sleep all alone on my own

My momma passed on last night

Why me?

Life goes on...

So I'm trying to get it on, man I'm doing all that I can,

But my mother on my mind, so I cry all day

My brother Wiseman tell me - life's useless, make it better if we can

I'm praying - Oh God, I need to be free from the world we're living in

Life's kinda hard, my credit came around

Be the mother on the side

This thing we call life comes once, then its gone

My momma came along in my dream as an angel

Only if you're here to see your son grow

And now I'm all alone with the big boy Plat

Anything is possible you said that last

Hey man, rest in peace to my mother, to my little sister,

Tell you about who passed on in my life - you gotta make it

it's your future, you know what I mean?

Now it's a must, we all have to make it, you got to push hard

\section{Acknowledgements Competing interests}

The author declares that she has no financial or personal relationship(s) which may have inappropriately influenced her in writing this article.

\section{References}

AIDS Foundation South Africa, 2005, HIV and AIDS in South-Africa, viewed 26 May 2009, from http://www.aids.org.za/hiv.htm\#top

Allen, S. \& Daly, K., 2007, The effects of father involvement: An updated research summary of the evidence inventory, Guelph, University of Guelph, FIRA-CURA.

Anupkumar, A., 2013, The concept of marginalization: Introduction to Sociology, Project 1, viewed 29 January 2013, from http://www.adityaanupkumar.com/files/ TheConceptOfMarginalization.pdf

Barolsky, V., 2003, Over extended AIDS Review, Centre for the Study of AIDS, University of Pretoria, Pretoria.

Browning, D.S., 1991, A fundamental practical theology, Fortress Press, Minneapolis.

Children on the Brink, 2004, A joint report of new orphan estimates and a framework for action, UNICEF, New York.
Cornell, M., Reid, G. \& Walker, L., 2003, Waiting to happen, Double Storey, Cape Town. Deininger, K., Garcia, M. \& Subbarao, K., 2003, 'AIDS-induced orphanhood as a systemic shock: Magnitude, impact and program inventions in Africa', World Development 31(7), 1201-1220. http://dx.doi.org/10.1016/S0305-750X(03)00061-5

Demmer, C., 2007, 'Grief is a luxury: AIDS-related loss among the poor in South Africa, Illness', Crisis and Loss 15(1), 39-51.

Denis, P., 2006, 'Death and memory in a time of AIDS', Children First 10(64), 27-35.

Denis, P. \& Ntsimane, R., 2005, 'Absent fathers: Why do men not feature in stories of families affected by HIV/AIDS in Kwa Zulu-Natal?', in L. Richter\& R. Morrell (eds.), Baba: Men and fatherhood in South Africa, pp. 13-25, HSRC Press, Cape Town.

Elfenbein, R., 2005, '"ABC": A gendered look at HIV prevention', AIDS Legal Network $1,10-13$.

Flouri, E., 2005, Fathering and child outcomes, John Wiley \& Sons, Hoboken. http:// dx.doi.org/10.1002/9780470713228

Foster, G., 2006, 'Children who live in communities affected by AIDS', Lance 367(9511), 700-701. http://dx.doi.org/10.1016/S0140-6736(06)68273-1

Freedman, J. \& Combs, G., 1996, Narrative Therapy: The social construction of preferred realities, W.W. Norton \& Company, New York.

Furstenberg, F.F. \& Harris, K.M., 1993, 'When and why fathers matter: Impacts of father involvement on the children of adolescent mothers, in R.I. Lerman \& T. Ooms (eds.), Young unwed fathers: Changing roles and emerging policies, pp. 117-138, Temple University Press, Philadelphia.

Geertz, C., 1991, The interpretation of cultures: Selected essays, Fontana, London. PMid:1648674

Geffen, N., 2008, 'What do South Africa's AIDS statistics mean?' A TAC briefing paper, in Treatment Action Campaign, viewed 22 September 2009, from http://www.tac. org.za/community/node/2552

Goldenberg H. \& Goldenberg, I., 2008, Family Therapy: An overview, Thomson Brooks, Pacific Grove.

Harvey, E. \& Kehler, J., 2005, 'Sex and Sexuality in the context of HIV and AIDS', AIDS Legal Network 1, 1-6.

Hetherington, E.M. \& Stanley-Hagan, M.M., 1997, 'The effects of divorce on fathers and their children', in M.E. Lamb (ed.), The role of the father in child development, 3rd edn., pp. 191-211, John Wiley \& Sons, Inc., New York.

Hoffmann, M., 1971, 'Identification and conscience development', Child Development 42, 1071-1082. http://dx.doi.org/10.2307/1127793

Jaffe, S.R., Moffit, T.E., Caspi, A. \& Taylor, A., 2003, 'Life with (or without) father: The benefits of living with two biological parents depend on the father's antisocial behavior', Child Development 74(1), 109-126. http://dx.doi.org/10.1111/14678624.t01-1-00524

Joint United Nations Programme on HIV/AIDS, 2008, Report on the global HIV/AIDS epidemic: Executive summary, UNAIDS, Geneva.

Loubser, J. \& Müller, J.C., 2011, 'The use of metaphors in Narrative Research in exploring and describing experiences of adolescent male orphans affected by HIV and AIDS', HTS Teologiese Studies/Theological Studies 67(2), Art. \#1009, 9 pages. http://dx.doi.org/10.4102/hts.v67i2.1009

Morgan, A., 2000, What is narrative therapy? An easy-to-read introduction, Dulwich Centre Publications, Adelaide.

Moore, M.R. \& Chase-Lansdale, P.L., 2001, 'Sexual intercourse and pregnancy among African American girls in high-poverty neighborhoods: the role of family and perceived community environment', Journal of Marriage and Family 63, 11461157. http://dx.doi.org/10.1111/j.1741-3737.2001.01146.x

Morrell, R., 2006, 'Fathers, fatherhood and masculinity in South Africa', in R. Morrell \& L. Richter (eds.), Baba: Men and Fatherhood in South Africa, pp. 13-25, HSRC Press, Cape Town.

Mtimkulu, J., 2006, 'Promoting men's involvement in the care and protection of children', Children First 10(64), 38-39.

Müller, J.C., 2005, 'A postfoundationalist, HIV-positive practical theology', Practical Theology in South Africa 20(2), 72-88.

Müller, J.C., 2009, 'Transversal Rationality as a practical way of doing interdisciplinary work, with HIV and AIDS as a case study', Practical Theology in South Africa 24(2), 199-228.

Rao Gupta, G., 2002, 'Gender, sexuality, and HIV/AIDS: The what, the why, and the how', Plenary Address for the XIIIth International AIDS Conference, 12 July 2000 Durban South Africa, International Centre for Research on Women, Washington DC, viewed 28 June 2010, from http://www.icrw.org/docs/durban_hivaids speech700.pdf

Ruland, C.D., Finger, W., Williamson, N., Tahir, S., Savariaud, S., Schweitzer, A. \& Shears, K.H., 2005, Adolescents: Orphaned and vulnerable in the time of HIV/AIDS, Family Health International, Arlington.

Statistics South Africa, 2008, General Household Survey (GHS) 2007, StatsSA, Pretoria/ Cape Town.

Struwig, F.W. \& Stead, G.B., 2007, Planning, designing and reporting research, Pearson Education South Africa, Cape Town. PMid:18158668

Thrift, E. \& Amundson, N., 2007, 'Shaping the Story: A guide to facilitating narrative counselling', in K. Maree (ed.), Theoretical underpinning and practical application of hermeneutic-narrative approach to career counselling, pp. 39-50, Van Schaik Publishers, Pretoria.

Van Huyssteen, J.W., 1997, Essays in postfoundationalist theology, Eerdmans Publishing Company, Grand Rapids.

Vetten, L. \& Bhana, K., 2003, 'Violence, vengeance and gender: A preliminary investigation into the links between violence against women and HIV/AIDS in South Africa', in People Opposing Woman Abuse, viewed 01 July 2010, from http://www.powa.co.za/Display.asp?ID=21

Whitley, B.E., 2002, Principles of research in behavioral science, 2nd edn., ' McGrawHill, New York. 